\title{
Gelatin protein-mediated direct aldol reaction
}

by Dennis Kühbeck ${ }^{a}$ ), Jürgen Bachl ${ }^{\dagger a}$ ), Eva-Maria Schön ${ }^{\dagger a}$ ), Vicente Gotor-Fernández ${ }^{\mathrm{b}}$ ) and David Díaz Díaz*a) ${ }^{\mathrm{c}}$ )

a) Universität Regensburg, Institut für Organische Chemie, Universitätsstr. 31, Regensburg 93053, Germany (phone: + 49-941-943-4373; fax: + 49-941-943-4121; e-mail: David.Diaz@chemie.uniregensburg.de)

b) Universidad de Oviedo, Departamento de Química Orgánica e Inorgánica, Avenida Julián Clavería s/n, Oviedo 33071, Spain

c) IQAC-CSIC, Jordi Girona 18-26, Barcelona 08034, Spain

$\dagger$ ) Both authors have contributed equally to this work

Gelatin protein was found to catalyze the aldol reaction between cyclohexanone and different aromatic aldehydes under mild reaction conditions. The aldol additions carried out in DMSO at $37^{\circ} \mathrm{C}$ yielded the cross-condensation products with moderate diastereoselectivities favoring the syn isomers. Appropriate control experiments demonstrated the activity of the protein in the aldol condensation. The kinetic study of the model reaction between 4-nitrobenzaldehyde and cyclohexanone established a first-order rate constant of $k=(7.4 \pm 0.5) \times 10^{-3} \mathrm{~h}^{-1}$. Moreover, the scale-up of the process was successfully achieved at $1 \mathrm{~g}$ scale in comparable yield to the small scale.

Keywords: Aldol reaction; Gelatin; C-C bond formation; Biocatalysis 
Introduction. - Since the first report in 1872 [1], the aldol reaction between two carbonyl compounds has become one of the most powerful $\mathrm{C}-\mathrm{C}$ bondforming methods in organic synthesis. During the last decades, a number of different systems, including small molecules, polymers, enzymes and antibodies, have been reported to serve as efficient catalysts for this important reaction [2-5].

Within this context, and motivated by the production of value-added products from sustainable resources, we decided to explore the potential of gelatin as a natural organocatalyst for $\mathrm{C}-\mathrm{C}$ bond-formation. Gelatin is a biodegradable protein (50-100 KD) obtained either by acid (type-A) or alkaline (type-B) processing of collagen, which is the main component of connective tissues and the most abundant protein in mammals. The average amino acid composition often follows the pattern Gly-Pro-X and Gly-X-Hyp, where $\mathrm{X}$ is any other amino acid. In general, commercial samples contain Gly 23\%, Pro 12\%, and Hyp $\sim 11 \%$ of the total amino acid content. It should be noted that these values might vary depending on the source of the material and processing method [6]. The fact that some amino acids and peptides have been employed in different catalytic studies [2][7] motivated us to explore the potential ability of gelatin to promote some organic reactions. This protein has been traditionally used as a general ingredient in food, cosmetic, pharmaceutical and photographic industries [8], and only recently as a reducing ligand in the preparation of metal nanoparticles [9].

As a result of our research program, we have recently reported the condensation of nitroalkanes and aldehydes (Henry or nitroaldol reaction) catalyzed by gelatin and collagen proteins in both aqueous and organic media [10]. We have expanded here the potential of the gelatin protein, reporting the results obtained from the 
direct aldol reaction between cyclohexanone and different aromatic aldehydes in the presence of commercial gelatin under mild reaction conditions.

Results and Discussion. - Based on our previous experience and recent literature [10][11], the reaction between 4-nitrobenzaldehyde (1a, $0.1 \mathrm{mmol})$ and cyclohexanone (2) at physiological temperature was chosen as model aldol reaction to study the activity of the gelatin protein (i.e., gelatin from porcine skin type-A = PSTA). Preliminary screening of the reaction conditions (see Experimental Part) showed that $10 \mathrm{mg}$ of gelatin and 10-fold molar excess of 2 with respect to 1a were optimal to obtain the corresponding condensation product 3a in reasonable yields. Higher loadings did not significantly improve the results. For instance, the product yield obtained in the model reaction using 10 equivalents of 2 was ca. $62 \%$, whereas the use of 20 equivalents afforded the product in ca. $64 \%$ yield. In contrast, the use of only 5 equivalents of $\mathbf{2}$ decreased the yield to $38 \%$. Thus, further studies on the substrate scope were carried out using the mentioned pre-optimized conditions (Table 1).

Regarding the solvent, DMSO was found suitable for carrying out a comparative study. For instance, the product yield obtained in DMSO resulted ca. 4-fold higher than in water under the same conditions (entries 1-2). In contrast to our previous observations with the Henry (nitroaldol) reaction [10], the use of a phase transfer co-catalyst such as tetra- $n$-butylammonium bromide (TBAB) [12] did not improve the yield of the gelatin-mediated aldol reaction in water (entries 2-3). 
Table 1. Gelatin protein-catalyzed aldol reaction ${ }^{\mathrm{a}}$ )

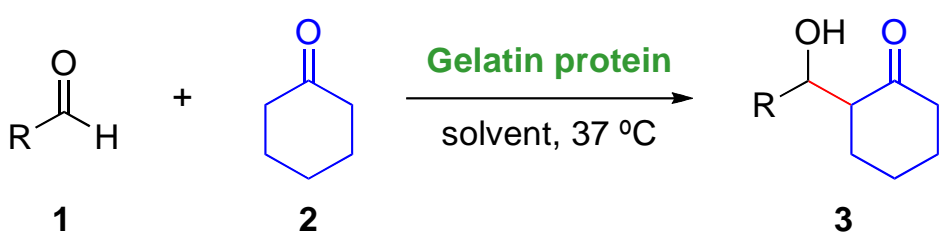

\begin{tabular}{|c|c|c|c|c|}
\hline Entry & $\mathrm{R}(\mathbf{1})$ & Solvent & Yield $\left.^{c}\right) \mathbf{3}[\%]$ & d.r. $\left.{ }^{\mathrm{d}}\right)[$ syn/anti] \\
\hline 1 & $\left(4-\mathrm{NO}_{2}\right)-\mathrm{C}_{6} \mathrm{H}_{4}(\mathbf{1 a})$ & DMSO & 62 & $3.9 / 1.0$ \\
\hline 2 & $\left(4-\mathrm{NO}_{2}\right)-\mathrm{C}_{6} \mathrm{H}_{4}(\mathbf{1 a})$ & $\mathrm{H}_{2} \mathrm{O}$ & 14 & $1.3 / 1.0$ \\
\hline 3 & $\left(4-\mathrm{NO}_{2}\right)-\mathrm{C}_{6} \mathrm{H}_{4}(\mathbf{1 a})$ & $\left.\mathrm{H}_{2} \mathrm{O}^{\mathrm{b}}\right)$ & 13 & $1.5 / 1.0$ \\
\hline 4 & $\left(3-\mathrm{NO}_{2}\right)-\mathrm{C}_{6} \mathrm{H}_{4}(\mathbf{1 b})$ & DMSO & 54 & $4.1 / 1.0$ \\
\hline 5 & $\left(2-\mathrm{NO}_{2}\right)-\mathrm{C}_{6} \mathrm{H}_{4}(\mathbf{1 c})$ & DMSO & 15 & $1.5 / 1.0$ \\
\hline 6 & $(4-\mathrm{NC})-\mathrm{C}_{6} \mathrm{H}_{4}(\mathbf{1 d})$ & DMSO & 52 & $4.2 / 1.0$ \\
\hline 7 & Pyrid-2-yl (1e) & DMSO & 24 & $3.6 / 1.0$ \\
\hline 8 & $\mathrm{C}_{6} \mathrm{H}_{5}$ (1f) & DMSO & 20 & $2.3 / 1.0$ \\
\hline 9 & $(4-\mathrm{Br})-\mathrm{C}_{6} \mathrm{H}_{4}(\mathbf{1 g})$ & DMSO & 34 & $2.8 / 1.0$ \\
\hline 10 & $\left(4-\mathrm{CH}_{3}\right)-\mathrm{C}_{6} \mathrm{H}_{4}(\mathbf{1 h})$ & DMSO & 10 & $2.2 / 1.0$ \\
\hline 11 & $\left(4-\mathrm{CH}_{3} \mathrm{O}\right)-\mathrm{C}_{6} \mathrm{H}_{4}(\mathbf{1 i})$ & DMSO & 5 & $2.5 / 1.0$ \\
\hline
\end{tabular}

a) Reaction conditions: $\mathbf{1}(0.1 \mathrm{mmol}), \mathbf{2}(1.0 \mathrm{mmol})$, PSTA $(10 \mathrm{mg})$, solvent $(0.5 \mathrm{~mL}), 37^{\circ} \mathrm{C}$ and 7 days at $250 \mathrm{rpm}$.

b) Reaction carried out in the presence of TBAB (13 mg, $0.04 \mathrm{mmol})$.

c) ${ }^{1} \mathrm{H}-\mathrm{NMR}$ yields that correspond to the average values of two independent experiments (standard deviation, STDV $= \pm 2 \%$ ).

d) Diastereomeric ratio syn/anti determined by ${ }^{1} \mathrm{H}-\mathrm{NMR}$ analyses of two independent experiments. Relative configurations were assigned by comparison with the data reported in the literature.

It is important to highlight that appropriate control experiments confirmed the catalytic activity of the protein. For instance, only a tiny amount of the aldol product 3a was detected when the model reaction between $\mathbf{1 a}$ and $\mathbf{2}$ was carried out either in DMSO or in water $(\mathrm{pH} \sim 5)$ for 7 days in the absence of gelatin (Scheme 1). In agreement with our previous studies on the Henry reaction [10], we could also exclude any catalytic effect on the aldol reaction possibly caused by 
other minor components (ca. 10\%) such as metal and ash impurities in the gelatin samples [9a][13]. On this subject, the aldol product was obtained in only $4 \%$ yield when the model reaction of $\mathbf{1 a}$ and $\mathbf{2}$ was performed only in the presence of metal ions as Lewis acids at the concentration reported to be present in gelatin samples (i.e., [metal] $\times 10^{-6} \mathrm{~mol} \mathrm{~L}^{-1}=3.92\left(\mathrm{Co}^{2+}\right) ; 5.0\left(\mathrm{Cu}^{2+}\right) ; 9.42\left(\mathrm{Fe}^{3+}\right) ; 2.62\left(\mathrm{Pd}^{2+}\right)$; $9.92\left(\mathrm{Ni}^{2+}\right)$ [13]. Most importantly, although the specific mechanism of gelatin catalysis remains unclear, a simple acid or base catalysis was ruled out by measuring the $\mathrm{pH}$ of the reaction medium $(\mathrm{pH} \sim 5-6)$. This was further supported by the comparable results obtained using gelatin samples with different isoelectric points (i.e., type-A, type-B), which was in agreement with our previous observations [10].

Scheme 1. Control Experiment in the Absence of Gelatin Protein

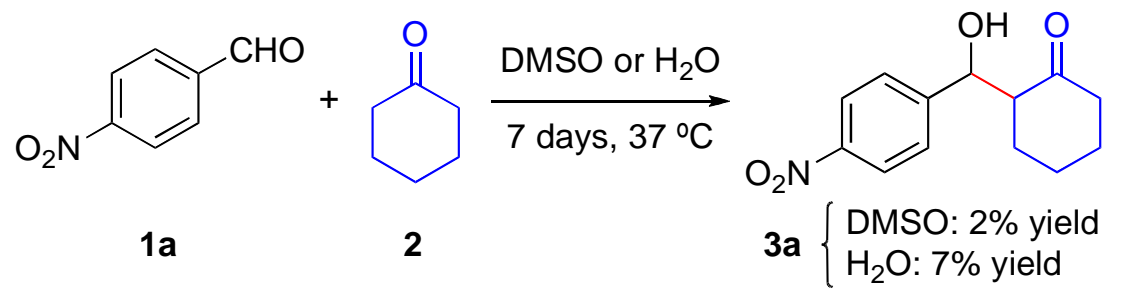

We further studied the gelatin-mediated reaction between different aldehydes 1a-i and 2 (Table 1). Herein, aromatic aldehydes with strongly or moderately deactivating groups (i.e., electron-withdrawing substituents) were smoothly converted into the corresponding $\beta$-hydroxy ketones in modest yields (entries 1 , 4, 5 and 6). The results also showed the influence of the substitution position on the product yield, leading to a significant decrease with the ortho-substituted aldehyde (1c, entries 1, 4 and 5). On the other hand, low yields were obtained 
with 2-pyridinecarbaldehyde (1e, entry 7), benzaldehyde (1f, entry 8), and in the cases of aromatic aldehydes bearing weakly or moderately activating groups (i.e., electron-donating substituents) (1g-i, entries 9-11). As observed with other aldollike reactions, these yields could be improved by increasing the reaction time and/or the temperature [10]. Unfortunately, aliphatic aldehydes such as isovaleraldehyde were not converted after 7 days under the reported conditions.

Interestingly, a modest syn diastereoselectivity was found in all cases (i.e., ca. 2-4-fold of syn vs anti), which is an uncommon feature in this reaction [2][3]. The diastereomeric ratio was reduced either in water, with orto-substituted aromatic aldehydes or with activated aromatic aldehydes. As expected due to the mild reaction conditions, no potential byproducts such as dehydrated or selfcondensation products were observed.

In concordance with our previous studies [10], the direct use of collagen also afforded the desired aldol product (e.g., 1a $(0.1 \mathrm{mmol}), 2(1.0 \mathrm{mmol})$, collagen (10 mg), DMSO $(0.5 \mathrm{~mL}), 7$ days, $37^{\circ} \mathrm{C}:$ Yield $=46 \%, d r($ syn/anti $\left.)=3.4 / 1.0\right)$.

It is also worth mentioning that the reaction can be scaled-up with comparable yields to the small scale (i.e., $1 \mathbf{a}(1.13 \mathrm{~g}, 7.5 \mathrm{mmol}), 2$ (7.75 mL, $75 \mathrm{mmol})$, PSTA gelatin (0.75 g), DMSO (38 mL), 7 days, $37{ }^{\circ} \mathrm{C}$, ca. $58 \%$ yield). In terms of recycling, gelatin was quantitatively recovered and reused in at least two consecutive runs with maintenance of stereoselectivity. Nevertheless, a major catalyst deactivation was observed in the third run (Figure 1). This is presumably due to inefficient molecular desorption from the catalyst, instead of decomposition, as suggested by a visible gradual color change (from light-yellow to intense yellow-orange) and similar FT-IR spectra of the washed-dried catalyst 
after each run. Either acetone or ethanol could be used to precipitate the protein from DMSO, which was further separated by centrifugation. Alternatively, direct extraction of the aqueous solutions with EtOAc allows the simple isolation and subsequent reuse of the protein-containing aqueous solution in the next cycle.

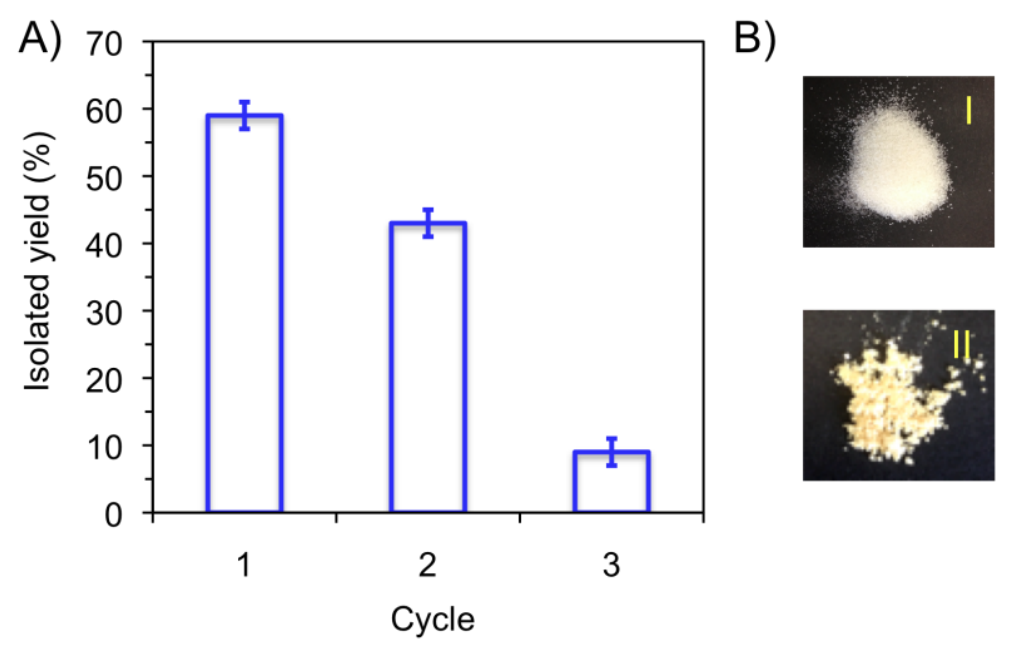

Figure 1. A) Recycling experiment for the model reaction between $\mathbf{1 a}(7.5 \mathrm{mmol})$ and $\mathbf{2}$ (75 mmol) catalyzed by PSTA gelatin $(0.75 \mathrm{~g})$ in DMSO (38 $\mathrm{mL})$ at $37^{\circ} \mathrm{C}$ for 7 days. B) Gradual coloring and apparent clogging of gelatin. I: Gelatin before $1^{\text {st }}$ run; II: Washed-dried gelatin after $3^{\text {rd }}$ run

Despite the chiral secondary structure of gelatin and collagen proteins, chiral high-performance liquid chromatography of the reaction mixtures revealed almost negligible enantioselectivity (i.e., $<5 \%$ ee for the major diastereomer, syn) during the aldol reaction. This lack of enantioselectivity has been also reported with other proteins or biopolymers when used as catalysts in aldol-like reactions $[10][11][14]$. In contrast to the results reported with other biocatalysts [15], the reduction of the temperature to $20^{\circ} \mathrm{C}$ did not caused any increase of the enantiomeric selectivity. 
The first-order kinetic analysis of the model reaction between $1 \mathbf{a}$ and 2 established a slow rate constant of $k=(7.4 \pm 0.5) \times 10^{-3} \mathrm{~h}^{-1}$ (Figure 2). It is worthwhile to mention that the morphology and/or physical state of a protein catalyst may also play a significant role in the kinetics of aldol-like reactions under heterogeneous or semi-heterogeneous conditions [10].

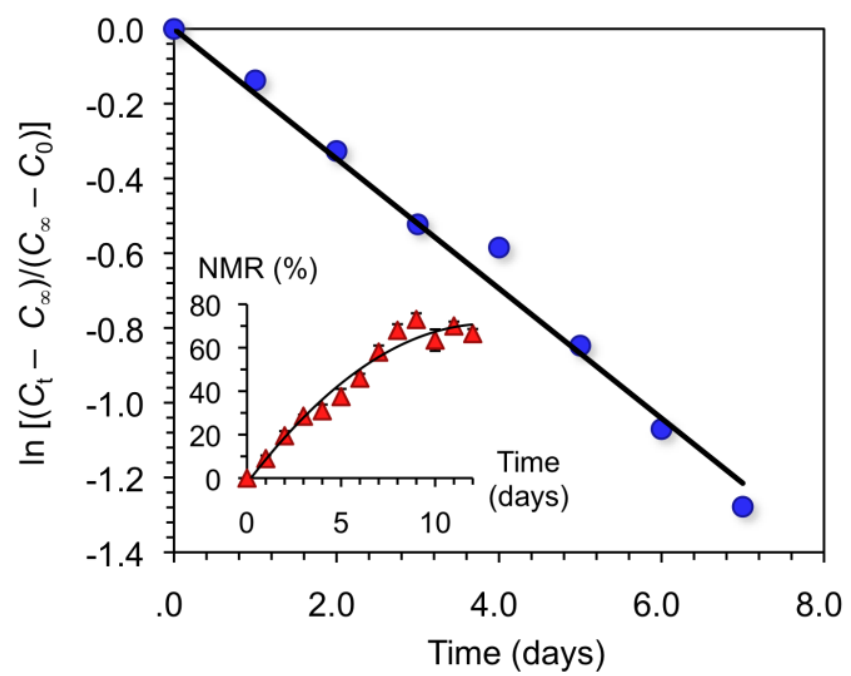

Figure 2. First-order kinetics plot of the model aldol reaction between $\mathbf{1 a}$ and $\mathbf{2}$ catalyzed by gelatin. $C_{\infty}=$ final concentration, at infinite time; $C_{t}=$ concentration at given time $t ; C_{0}=$ initial concentration, at $t=$ zero time. $R^{2}=0.98$. Inset: Evolution of reaction conversion over time

Conclusions. - In summary, we have demonstrated that $\mathrm{C}-\mathrm{C}$ bond formation through direct aldol reaction between cyclohexanone and different aromatic aldehydes can be promoted by commercial gelatin in organic medium under mild conditions. The corresponding condensation products were obtained in modest yields governed by first-order kinetics. In general, modest $s y n$ diastereoselectivity and complete chemoselectivity were also observed, demonstrating the applicability of the catalytic system in a gram-scale experiment. Moreover, the 
protein could be recovered at the end of the reaction and reused in at least two consecutive cycles without major disruption of the catalytic activity. Finally, we would like to emphasize that these and our previous investigation indicate that although edible gelatin is not a competitive catalyst for this type of reactions from a synthetic perspective, the fact that it can mediate to some extent (even under aqueous conditions) the transformation of carbonyl compounds existing in numerous foods or cosmetic formulations could be significant from a metabolic point of view.

Financial support of this work by Universität Regensburg (DDD, Förderlinie C des Finanziellen Anreizsystems für Drittmitteleinwerbung) is gratefully acknowledged. DDD thanks the DFG for the Heisenberg Professorship Award.

\section{Experimental Part}

Materials. Analytical grade solvents and commercially available reagents were purchased from Sigma Aldrich or TCI Europe and used as received. Milli-Q water was used for the experiments in aqueous solutions. Gelatin porcine skin type-A was purchased from Sigma Aldrich (CAS 9000-708; Cat. No. G2500-100G; Batch No. 128K0066; Type A, derived from acid-cured tissue; ca. 300 Bloom; 79\% protein content by Buiret) and used without further purification. Collagen was purchased from Sigma Aldrich (CAS 9007-34-5; Cat. No. C9879-1G; Batch No. 061M7015V; Type A, derived from bovine achilles tendon). A detailed description of the most important features of both gelatin and collagen can be found in the Supporting Information of our previous work focused on the nitroaldol (Henry) reaction catalyzed by these proteins [10].

Methods. ${ }^{1} \mathrm{H}$-NMR spectra were recorded on a Bruker Avance 300 spectrometer at $25{ }^{\circ} \mathrm{C}$. TLC analyses were carried out on fluorescent-indicating plates (aluminium sheets precoated with silica gel 60 F254, Merck) and the products visualized by the use of the phosphomolybdic acid as stain solution and UV light $(254 \mathrm{~nm})$. The reaction mixtures were analyzed using a Varian 920-LC Liquid Chromatograph (column Phenomenex Lux Cellulose-2, $4.6 \times 250 \mathrm{~mm}, 5 \mu \mathrm{m}$; eluent: $n$ - 
heptane:i-PrOH 70:30; flow $1.0 \mathrm{~mL} / \mathrm{min} ; \lambda=254 \mathrm{~nm}$ ). FT-IR spectra were recorded using a Diamond ATR (attenuated total reflection) accessory (Golden Gate). The surface morphology of the catalyst was observed with a Carl Zeiss Merlin field emission scanning electron microscope (FESEM, resolution $0.8 \mathrm{~nm}$ ) equipped with a digital camera and operating at an accelerating voltage of $5 \mathrm{kV}$ and an emission current of $10 \mu \mathrm{A}$. The powdered sample was placed on top of a tin plate and shielded by Pt at $40 \mathrm{~mA}$ during $30 \mathrm{~s}$ to obtain a film thickness of ca. $5 \mathrm{~nm}$.

Yields were determined by ${ }^{1} \mathrm{H}-\mathrm{NMR}$ analyses of the crude product in $\mathrm{CDCl}_{3}$ using diphenylmethane $(1 \mathrm{~mL}$ of a $0.1 \mathrm{M}$ stock solution) as internal standard. The results were confirmed by a second experiment using directly dimethylacetamide $(9.2 \mathrm{~mL}$, added using a Hamilton syringe) as internal standard. Thus, possible concentration variations of the stock solution of diphenylmethane in $\mathrm{CDCl}_{3}$ could be detected and the values crosschecked. Relative configurations were assigned by comparison with ${ }^{1} \mathrm{H}-\mathrm{NMR}$ data reported in the literature [16]. For kinetics calculations, the ${ }^{1} \mathrm{H}-\mathrm{NMR}$ analyses of the reaction mixtures were performed in the presence of diphenylmethane $(0.1 \mathrm{mmol})$ as internal standard. Each experimental point was given as the average of at least two independent experiments. Among various kinetics models, the straight line shown in the kinetics plot show best-fit of the first-order model (i.e., [cyclohexanone] $\geq$ [aldehyde]).

Copies of NMR and IR spectra can be obtained directly on request to the authors.

Preliminary optimization experiments: A) Screening of cyclohexanone (2) equivalents: The model reaction between 1a $(15.1 \mathrm{mg}, 0.1 \mathrm{mmol})$ and $\mathbf{2}(5,10$ and 20 equivalents) was carried out in DMSO $(0.5 \mathrm{~mL})$ at $37^{\circ} \mathrm{C}$ for 7 days in the presence of PSTA gelatin $(10 \mathrm{mg})$. The results showed that the aldol product 3a was obtained in 38\%, 62\% and 64\% yield, respectively. B) Screening of catalyst loading: Table 2 shows the results of selected experiments for the reaction between 1a $(0.1 \mathrm{mmol})$ and $2(2 \mathrm{mmol})$ in DMSO $(0.5 \mathrm{~mL})$ under different conditions of solvent temperature, reaction time and catalyst loading.

Table 2. Initial screening of catalyst loading ${ }^{\mathrm{a}}$ )

\begin{tabular}{llllll}
\hline Entry & Solvent & Temperature $\left[{ }^{\circ} \mathrm{C}\right]$ & Time [days $]$ & Catalyst loading $[\mathrm{mg}]$ & Yield 3a [\%] \\
\hline 1 & DMSO & 25 & 14 & 0 & 2 \\
2 & DMSO & 25 & 18 & 5 & 27
\end{tabular}




\begin{tabular}{clllll}
3 & $\mathrm{DMSO}$ & 25 & 14 & 10 & 62 \\
\hline 4 & $\mathrm{H}_{2} \mathrm{O}$ & 25 & 21 & 0 & 2 \\
5 & $\mathrm{H}_{2} \mathrm{O}$ & 37 & 7 & 0 & 7 \\
6 & $\mathrm{H}_{2} \mathrm{O} / \mathrm{TBAB}$ & 37 & 7 & 0 & 5 \\
\hdashline 7 & $\mathrm{H}_{2} \mathrm{O}$ & 25 & 21 & 5 & 2 \\
8 & $\mathrm{H}_{2} \mathrm{O}$ & 37 & 7 & 10 & 14
\end{tabular}

a) The use of more than $10 \mathrm{mg}$ of PSTA makes the work-up of the reaction more laborious

General Procedure for Gelatin-catalyzed Aldol Reaction: Cyclohexanone (104 $\mu \mathrm{L}, 1.0 \mathrm{mmol})$ was added in one portion to a $4 \mathrm{~mL}$ screw cap vial containing 4-nitrobenzaldehyde $(15 \mathrm{mg}, 0.1$ mmol), gelatin porcine skin type-A $(10 \mathrm{mg})$ and DMSO $(0.5 \mathrm{~mL})$. The mixture was stirred $(250$ rpm) for 7 days at $37{ }^{\circ} \mathrm{C}$. The reaction was quenched by the addition of EtOAc $(1 \mathrm{~mL})$ and EtOH $(1 \mathrm{~mL})$ and subsequent filtration of the precipitated catalyst. The filtrate was rinsed three times with EtOAc $(3 \times 1 \mathrm{~mL})$ and the combined organic phases washed with $\mathrm{H}_{2} \mathrm{O}(2 \times 5 \mathrm{~mL})$ and brine (5 mL), dried over $\mathrm{Na}_{2} \mathrm{SO}_{4}$, filtrated and evaporated under reduced pressure to afford the crude product. Yield and diastereomeric ratio (syn/anti) were determined by ${ }^{1} \mathrm{H}-\mathrm{NMR}$ analyses of the crude product in $\mathrm{CDCl}_{3}(300 \mathrm{MHz})$ using diphenylmethane $(1 \mathrm{~mL}$ of a $0.1 \mathrm{M}$ stock solution) as internal standard after complete work-up of the reaction. Relative configurations were assigned by comparison with the spectroscopy data reported in the literature. For instance, in the model reaction reaction between $\mathbf{1 a}$ and $\mathbf{2}$, the anti diastereomer was clearly identified by a doublet at $4.85 \mathrm{ppm}(1 \mathrm{H}, J=8.3 \mathrm{~Hz})$, whereas the $s y n$ diastereomer displayed the doublet at $5.41 \mathrm{ppm}(1 \mathrm{H}, J$ $=2.4 \mathrm{~Hz})$. Typically, for recycling experiments acetone or EtOH ( $1 \mathrm{~mL}$ per $2 \mathrm{mg}$ of catalyst $)$ was added in order to precipitate the gelatin from DMSO. The protein was subsequently separated by centrifugation (10 min, $3800 \mathrm{rpm})$-washing with EtOAc $(2 \mathrm{~mL})$-centrifugation cycles. The obtained residue was finally dried under vacuum before the next catalytic cycle.

\section{REFERENCES}

[1] A. Wurtz, Bull. Soc. Chim. Fr. 1872, 17, 436.

[2] B. M. Trost, C. S. Brindle, Chem. Soc. Rev. 2010, 39, 1600, and references therein. 
[3] T. D. Machakewski, C.-H. Wong, Angew. Chem. Int. Ed. 2000, 39, 1352, and references therein.

[4] R. Mahrwald, Modern Methods in Stereoselective Aldol Addition, 1st Ed. Wiley-VCH Verlag GmBH, 2013.

[5] K. Fesko, M. Gruber-Khadjawi, ChemCatChem 2013, 5, 1248.

[6] R. N. R. M. Hafidz, C. M. Yaakob, I. Amin, A. Noorfaizan, Int. Food Res. J. 2011, 18, 813. R. Schrieber, H. Gareis, Gelatine Handbook: Theory and Industrial Practice, 1st Ed., WileyVCH Verlag GmbH, 2007.

[7] R. Mahrwald, Org. Lett. 2012, 14, 2180; D. Deng, P. Liu, B. Ji, W. Fu, L. Li, Catal. Lett. 2010, 137, 163; Z. Jiang, H. Yang, X. Han, J. Luo, M. W. Wong, Y. Lu, Org. Biomol. Chem. 2010, 8, 1368; K. Rohr, M. Amedjkouh, Tetrahedron: Asymmetry 2007, 18, 390; D.-S. Deng, J. Cai, Helv. Chim. Acta 2007, 90, 114; T. Nagamine, K. Inomata, Y. Endo, L. A. Paquette, J. Org. Chem. 2007, 72, 123; N. Mase, Y. Nakai, N. Ohara, H. Yoda, K. Takabe, F. Tanaka, C. F. Barbas III, J. Am. Chem. Soc. 2006, 128, 734; A. Córdova, W. Zou, P. Dziedzic, I. Ibrahem, E. Reyes, Y. Xu, Chem. Eur. J. 2006, 12, 5383.

[8] A. Imeson, Food stabilisers, thickeners and gelling agents, Wiley-Blackwell Pub., Chichester, U.K., 2010.

[9] H. Firouzabadi, N. Iranpoor, A. Ghaderi, Org. Biomol. Chem. 2011, 9, 865; H. Firouzabadi, N. Iranpoor, A. Ghaderi, J. Mol. Catal. A: Chem. 2011, 347, 38; S.-Z. Kang, T. Wu, X. Li, J. Mu, Colloids Surf. A 2010, 369, 268.

[10] D. Kühbeck, B. B. Dhar, E.-M. Schön, C. Cativiela, V. Gotor-Fernández, D. D. Díaz, Beilstein J. Org. Chem. 2013, 9, 1111.

[11] D. Kühbeck, G. Saidulu, K. R. Reddy, D. D. Díaz, Green Chem. 2012, 14, 378.

[12] L. Mhamdi, H. Bohli, Y. Moussaoui, R. ben Salem, Int. J. Org. Chem. 2011, 1, 119.

[13] C. V.-L. Bray, F. Jiang, X.-F. Wu, J.-B. Sortais, C. Darcel, Tetrahedron Lett. 2010, 51, 4555.

[14] S. E. Milner, T. S. Moody, A. R. Maguire, Eur. J. Org. Chem. 2012, 3059; M. S. Humble, P. Berglund, Eur. J. Org. Chem. 2011, 3391; E. Busto, V. Gotor-Fernández, V. Gotor, Chem. Soc. Rev. 2010, 39, 4504; Q. Wu, B.-K. Liu, X.-F. Lin, Curr. Org. Chem. 2010, 14, 1966; J. Fan, G. Sun, C. Wan, Z. Wang, Y. Li, Chem. Commun. 2008, 3792; 
[15] H.-H. Li, Y.-H. He, Z. Guan, Cat. Commun. 2011, 12, 580.

[16] S. Paladhi, J. Das, P. K. Mishra, J. Dash, Adv. Synth. Catal. 2013, 355, 274; Z.-B. Xie, N. Wang, G.-F. Jiang, X.-Q. Yu, Tetrahedron Lett. 2013, 54, 945; R. Pedrosa, J. M. Andrés, R. Manzano, P. Rodríguez, Eur. J. Org. Chem. 2010, 5310; A. Ricci, L. Bernardi, C. Gioia, S. Vierucci, M. Robitzer, F. Quignard, Chem. Commun. 2010, 46, 6288. 
Table of Contents

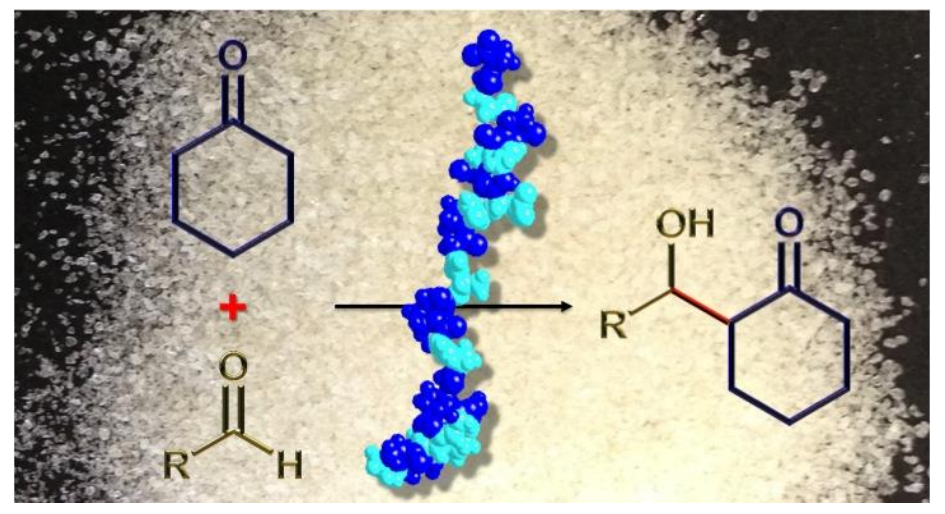

